\title{
Improved DNA Extraction Method for Molecular Diagnosis from Smaller numbers of Cells
}

\author{
Seo Young $\mathrm{Oh}^{1,2}$, Jeong Yeon $\mathrm{Han}^{3}$, So Ra Lee ${ }^{1}$ and Hoon Taek Lee ${ }^{2}$ \\ ${ }^{1}$ Department of Pathology, Konkuk University Medical Center, Seoul 143-729, Korea \\ ${ }^{2}$ Department of Animal Biotechnology, College of Animal Bioscience \& Technology Konkuk University, Seoul 143-701, Korea \\ ${ }^{3}$ Department of Pathology, Seoul National University Hospital, Seoul 110-744, Korea
}

\begin{abstract}
Isolating total DNA from small samples using traditional methods is difficult and inefficient mainly due to loss of DNA during filtration and precipitation. With advances in molecular pathology, DNA extraction from micro-dissected cells has become essential in handling clinical samples. Genomic DNA extraction using small numbers of cells can be very important to successfully PCR amplify DNA from small biopsy specimens. We compared our experimental genomic DNA extraction method (A) with two other commercially available methods: using spin columns (B), and conventional resins (C), and determined the efficacy of DNA extraction from small numbers of cells smeared on a glass slide. Approximately 50, 100, 200, 500 and 1000 cells were isolated from fine needle aspiration biopsy (FNAB) slides aspirated from histologically proven papillary thyroid carcinoma masses. DNA was extracted using the three techniques. After measuring DNA quantity, PCR amplification was performed to detect the $\beta$-globin and $B R A F^{V 600 E}$ gene mutations. DNA extracted by method (A) showed better yield than the other methods in all cell groups. With our method, a suitable amount of genomic DNA to produce amplification was extracted from as few as 50 cells, while more than 100 to 200 cells were required when methods (B) or (C) were applied. Our genomic DNA extraction method provides high quality and improved yields for molecular analysis. It will be especially useful for paucicellular clinical samples which molecular pathologists often confront when handling fine needle aspiration cytology, exfoliative cytology and small biopsy specimens.
\end{abstract}

Keywords: Paucicellular clinical samples, DNA extraction method, DNA quantity

This is an Open Access article distributed under the terms of the Creative Commons Attribution Non-Commercial License (http://creativecommons.org/licenses/by-nc/3.0) which permits unrestricted non-commercial use, distribution, and reproduction in any medium, provided the original work is properly cited.

Copyright (C) 2014 The Korean Society for Clinical Laboratory Science. All rights reserved.
Corresponding author: Seo Young Oh Department of Pathology, Konkuk University Medical Center, 4-12 Hwayang-dong, Gwangjin-gu, Seoul 143-729, Korea Tel: 82-2-2030-5631

E-mail: syoh@kuh.ac.kr

Received: August 12, 2014

Revised: September 17, 2014

Accepted: September 29, 2014

\section{Introduction}

Molecular diagnosis combines molecular biology techniques with knowledge of molecular mechanisms of disease to diagnose causes of illness and support therapeutic decision-making. It uses diagnostic assays based on nucleic acid extraction, and probes DNA or RNA directly from tissue sections or cytological preparation (Salto-Tellez and Koay, 2004).

Molecular diagnosis of cancer often requires isolation of genomic DNA from paucicellular clinical samples including fine needle aspirates, nipple fluid aspirates, sputum, buccal swabs, cervical smears, and urine (Walker et al, 1999; Kersting et al, 2000; Phillips et al, 2000; Seripa et al, 2001; Bofin et al, 2004; Isaacs et al, 2004). If high quality amplifiable DNA can be extracted from these samples, it is often subjected to $\mathrm{LOH}$ analysis, gene copy number determination, genotyping, mutational analysis, or promoter methylation studies (Phillips et al, 2000; Euhus et al, 2002; Bu et al, 2003; Wang et al, 2003; Zhang et al,2003; Lewis et al, 2005).

Isolating DNA from very small quantities of sample using traditional methods is difficult and inefficient primarily due to losses during filtration and precipitation. This often results in poor yields of amplifiable DNA when the starting material is limited. With advances in molecular pathology, DNA extraction from micro-dissected cells has become essential 
for clinical samples.

Genomic DNA extraction from small numbers of cells is the most important step for amplifying DNA by PCR from cytological and small biopsy specimens (Cler et al, 2006). Recently, several commercial DNA extraction kits have become available and are promoted as alternatives to organic extraction as a mean of preparing DNA for amplification. They include an ion exchange resin (DEXPAT ${ }^{\mathrm{TM}}$, Takara Bio. Inc., Japan), adsorption of DNA onto a silica membrane (pinpoint slide DNA isolation system ${ }^{\mathrm{TM}}$, Takara Bio. Inc., Japan), and a salting out procedure (Wizard Genomic DNA Purification Kit, Promega Corporation, USA). Important factors to consider in the evaluation of extraction procedures include DNA yield and purity, suitability of the DNA for amplification, time required to perform extraction, the number of transfer steps, and the cost of the method (Vandenberg et al, 1997).

We compared our homemade-preparation method with two other commercially available kits that use spin columns or conventional resin-based methods. We evaluated the quantity and quality of DNA by spectrophotometer readout, $\beta$-globin amplification, and $B R A F^{V 600 E}$ mutational analysis. For this evaluation, we extracted each DNA from different quantities of the human papillary thyroid carcinoma (PTC) cells smeared on a glass slide using the three extraction techniques.

\section{Materials and Methods}

\section{Cells}

Patients with papillary thyroid carcinoma (PTC) cells on fine needle aspiration (FNA) smeared cytology slide from the files of the department of pathology of the Konkuk University medical center of 8 years old (2005) Study approval was obtained from the Institutional Review Board (KUH 1210002). We used papillary thyroid carcinoma (PTC) cells smeared on a glass slide in routine fine needle aspiration cytology (FNAC) specimens as study samples. In PTC cells of fine needle aspiration (FNA), tumor cells were aspirated using a 26 gauge needle from the thyroid gland under ultrasound guidance and were smeared on a glass slide. The smeared FNAC slide was stained by the Papanicolau procedure. After marking the target cells by the pathologist, the cover slide was removed in xylene, and finally air dried. Since dried smeared cells do not display well and fine cytological details and are too brittle to scrape, the slide was rinsed in a $2 \%$ glycerol in TE buffer (10 mM Tris-HCl pH 8.5, 1 mM EDTA, pH 8.0) for 2 min. The wet condition provides good cytomorphological details and the target cells are easy to scrape.

To compare of three different DNA extraction method, tumor cells were aspirated using a 26 gauge needle from fresh PTC masses and where smeared on a glass slide. Approximately 50, 100, 200, 500, or 1000 cells were dissected and DNA was extracted using three different techniques. After measuring DNA concentration and purity, PCR amplification for the $\beta$-globin and $B R A F^{\mathrm{V} 600 \mathrm{E}}$ gene mutations was performed.

\section{DNA Extraction}

\section{1) KUMC chelex method}

Briefly, 30 50 $\mu \mathrm{L}$ of our homemade extraction buffer solution (Tris- $\mathrm{HCl},\left(\mathrm{NH}_{4}\right)_{2} \mathrm{SO}_{4}$, EDTA, Tween-20 ; alkaline condition) with 10\% Chelex-100 (Bio-rad, USA) was added to the dissected cells in a $0.2 \mathrm{~mL}$ PCR tube, and proteinase $\mathrm{K}$ (Takara Bio. Inc., Japan) was added to a final concentration of $200 \mu \mathrm{g} / \mathrm{mL}$ then digested at $56^{\circ} \mathrm{C}$ for a minimum of 1 hour. Following incubation, the $0.2 \mathrm{~mL}$ PCR tubes were heated to $100^{\circ} \mathrm{C}$ for 20 minutes in a PTC-220 thermocycler (Bio-Rad, USA) and were centrifuged at $12,000 \mathrm{rpm}$ for 10 minutes. Two to five microliter of the supernatant was used in each PCR reaction.

\section{2) Spin column method}

Dissected cells were treated according to the manufacturer's protocol for the pinpoint slide DNA isolation system $^{\mathrm{TM}}$ (Zymo research, USA), and $2 \sim 5 \mu \mathrm{L}$ of genomic DNA was used in the PCR reaction.

\section{3) Conventional resin method}

Dissected cells were heated to $100^{\circ} \mathrm{C}$ for 10 minutes with 30 50 $\mu \mathrm{L}$ of resin based DEXPAT ${ }^{\mathrm{TM}}$ kit solution (Takara Bio. Inc., Japan), tubes were centrifuged to pellet the debris, and $2 \sim 5 \mu \mathrm{L}$ 
of the supernatant was used in the PCR reaction.

\section{DNA Quantification}

DNA concentration was measured with a DU-500 spectrophotometer (Beckman Coulter, USA) at $260 \mathrm{~nm}$ wavelength using $2 \mu \mathrm{L}$ of sample. DNA purity was determined by calculating the absorbance ratio $\mathrm{A}_{260} / \mathrm{A}_{280}$. Pure DNA has a ratio of 1.8 \pm 0.2 (Popa et al, 2007; Daneshwar et al, 2004). The yield and purity of DNA was measured in triplicate.

\section{PCR Amplification of the $\beta$-globin Gene}

For $\beta$-globingene amplification, the forward primer $\mathrm{PC}-3$, 5'-ACACAACTGTGTTCACTAGC-3' and reverse primer PC-4, 5'-CAACTTCATCCACGTTCACC-3' were used which together amplify a 110-bp DNA fragment. Briefly, $2 \mu \mathrm{L}$ of DNA was added to a total $20 \mu \mathrm{L}$ PCR solution mixture containing 0.2 $\mathrm{mM}$ of each dNTP, $1.5 \mathrm{mM} \mathrm{MgCl}_{2}, 1 \times$ PCR buffer, $1.5 \mathrm{U}$ of Immolase DNA Taq. Polymerase (Bioline, UK) and 20 pmol of each primer. PCR was performed with an initial denaturation for 5 minutes at $95^{\circ} \mathrm{C}$ followed by 50 cycles $(30$ seconds at $95^{\circ} \mathrm{C}, 30$ seconds at $50^{\circ} \mathrm{C}, 30$ seconds at $72^{\circ} \mathrm{C}$ ) and incubation for 10 minutes at $72^{\circ} \mathrm{C}$. The PCR products were analyzed by agarose gel electrophoresis to confirm successful amplification.

\section{BRAF ${ }^{V 600 E}$ Mutational Analysis Using Pyrosequencing}

The primer sequences for the amplification of the BRAF $F^{V 600 E}$ mutation site were 5'-biotin-CTTCATAATGCTTGC TCTGATAGG-3' (F) and 5'-GGCCAAAAATTTAATCAGTGGA A-3' (R). Five microliters of DNA was added to a total $50 \mu \mathrm{L}$ PCR solution mixture containing $0.2 \mathrm{mM}$ of each dNTP, 1.5 $\mathrm{mM} \mathrm{MgCl} 2,1 \times$ PCR buffer, $1.5 \mathrm{U}$ of Immolase DNA Taq. polymerase, and $20 \mathrm{pmol}$ of each primer. PCR was carried out with an initial denaturation for 5 minutes at $95^{\circ} \mathrm{C}$ followed by 50cycles $\left(30\right.$ seconds at $95^{\circ} \mathrm{C}, 30$ seconds at $55^{\circ} \mathrm{C}$, and 30 seconds at $72^{\circ} \mathrm{C}$ ) and incubation for 10 minutes at $72^{\circ} \mathrm{C}$. The PCR products were analyzed by agarose gel electrophoresis to confirm successful amplification.

The biotinylated products were then immobilized to streptavidin-coated beads using solution from a commercial PSQTM96 sample preparation kit (Qiagen, UK). $3 \mu \mathrm{L}$ of beads were diluted in binding buffer with $10 \mu \mathrm{L}$ of biotinylated PCR products and incubated for 10 minutes at room temperature. The beads were then transferred to a filter probe and liquid was removed by vacuum filtration. The DNA in the denaturation solution was separated, templates were washed with washing buffer, transferred to a PSQ 96 SNP plate (Qiagen, UK)., and annealed with a sequencing primer in buffer at room temperature, 5'-CCACTCCATCGAGATTT-3'. Finally, the samples were analyzed using a PyroMark ID System (Qiagen, UK) with a SNP reagent kit for sequence analysis (Kim et al, 2008; Hwang et al, 2009).

\section{Results}

\section{Evaluation of Nucleic Acid}

In order to determine the best isolation protocol for nucleic acid from the paucicellular clinical samples, we compared three different DNA extraction techniques. Table 1 shows total genomic DNA yield and purity of samples extracted from various numbers of PTC cells smeared on a glass slide.

When we analyzed PTC cells smeared on the glass slide, the concentration of DNA ranged from 13.9 to $101.4 \mu \mathrm{g} / \mathrm{mL}$ for a

Table 1. Average concentrations of DNA extracted using three different techniques from various numbers of PTC cells smeared on glass slides

\begin{tabular}{crcc}
\hline \multirow{2}{*}{ Method } & Cell No. & \multicolumn{2}{c}{ FNA Smeared PTC Cell } \\
\cline { 3 - 4 } & & $\begin{array}{c}\text { DNA yield } \\
(\text { ng/uL) }\end{array}$ & $\begin{array}{c}\text { Purity } \\
A_{260} / A_{280}\end{array}$ \\
\hline A & 50 & 13.9 & 1.7 \\
& 100 & 25.9 & 1.5 \\
& 200 & 44.7 & 1.5 \\
& 500 & 72.8 & 1.8 \\
B & 1000 & 101.4 & 1.5 \\
& 50 & 1.6 & 1.2 \\
& 100 & 13.9 & 1.6 \\
& 200 & 18.7 & 1.8 \\
C & 500 & 34.7 & 1.6 \\
& 1000 & 60.6 & 1.8 \\
& 50 & 4.2 & 1.3 \\
& 100 & 21.2 & 1.6 \\
& 200 & 34.0 & 1.4 \\
& 500 & 47.4 & 1.7 \\
\hline
\end{tabular}

A, KUMC chelex method; B, Spin column method; C, Conventional resin method; PTC, Papillary Thyroid carcinoma; FNA, fine needle aspiration. 
KUMC chelex method, 1.6 to $60.6 \mu \mathrm{g} / \mathrm{mL}$ for a spin column method, and 4.2 to $76.7 \mu \mathrm{g} / \mathrm{mL}$ for a conventional resin method. The purity $\left(\mathrm{A}_{260} / \mathrm{A}_{280}\right)$ of DNA ranged from 1.5 to 1.8 for a KUMC chelex method, 1.2 to 1.8 for a spin column method, 1.3 to 1.7 for a conventional resin method.

Our KUMC chelex method showed better yield than the two other methods for all samples.

\section{Amount of Successful DNA Extraction in Paucicellular Samples}

To compare the quality of method for extracting DNA from various numbers of PTC cells smeared on glass slides, the $\beta$-globin gene was amplified from DNA extracted using each method. Using PTC cells smeared on glass slides, a suitable amount of genomic DNA for amplification was extracted from as few as 50 cells in a KUMC chelex method, whereas at least 100 to 200 cells were required to produce amplification with spin column or conventional resin method. Our KUMC chelex method provided superior quality and yield for molecular analysis (Fig. 1).

\section{Determining the Efficiency of DNA Extraction by examining the $B R A F^{V G O 0 E}$ Mutation}

To confirm the efficiency of our homemade-preparation method, we analyzed the BRAF $F^{V 600 E}$ sequence using the PyroMark ID System with a SNP reagent kit. When we used cells smeared on glass slides, the intensity of the " $\mathrm{T}$ " peak

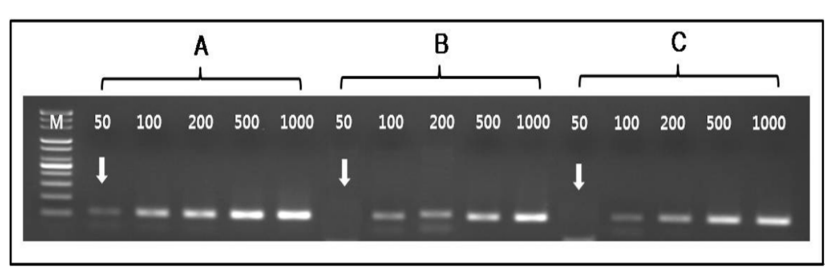

Fig. 1. Amplification of the $\beta$-globin gene using DNA extracted from different numbers of PTC cells smeared on glass slides. We compared PCR products amplified from DNA extracted using three different methods to determine the efficacy of DNA extraction. This assay uses $\beta$-globin primers that amplify a $110 \mathrm{bp}$ fragment from genomic DNA. A, KUMC chelex method; B, Spin column method; $\mathrm{C}$, Conventional resin method.

\section{No. of cell}

50

100

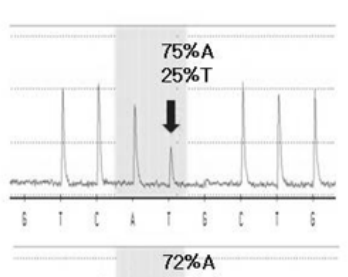

$28 \% \mathrm{~T}$

200
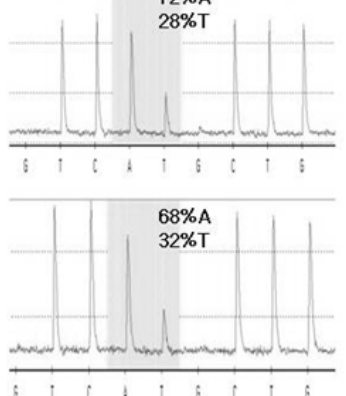

500

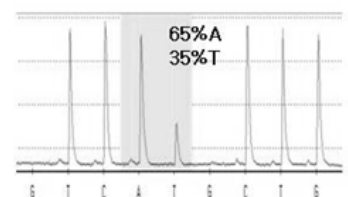

1000

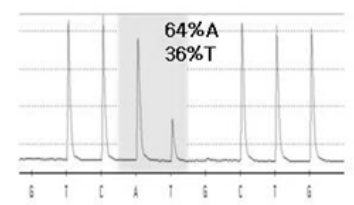

B

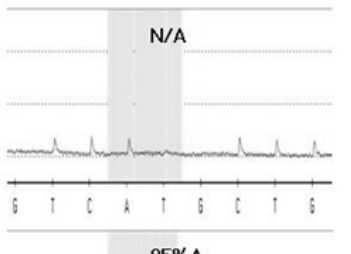

$85 \%$ A
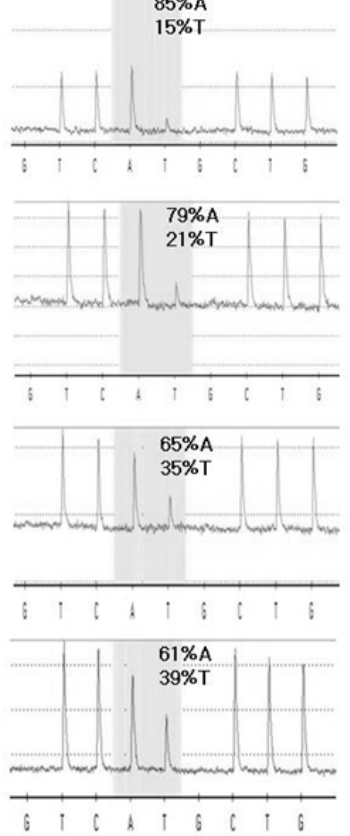

C

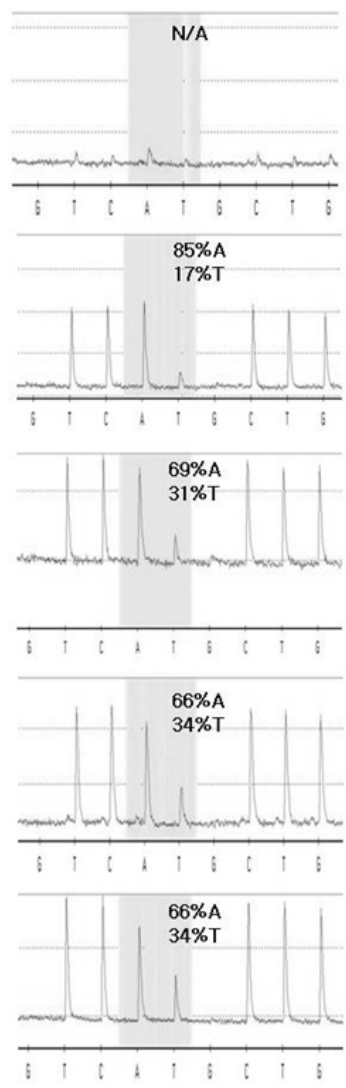

Fig. 2. A Determining the efficiency of DNA extraction by examining the $B R A F^{V 600 E}$ mutation in different numbers of PTC cells smeared on glass slides. Comparison of a KUMC chelex method (A) with a spin column method (B) and a conventional resin method (C). N/A, not applicable. 
signal height ranged from 25 to 36\% with a KUMC chelex method, none to $39 \%$ with a spin column method, and none to $34 \%$ with a conventional resin method. When only 50 cells were extracted a KUMC chelex method could detect both a "T" peak (25\%) increase and adjacent "A" peak (75\%) decrease, while sequence peaks were too low to be analyzed using the two other methods. When 100 cells were extracted a KUMC chelex method showed a significant increase of " $\mathrm{T}$ " peak signal height and decrease of "A" peak signal, while T peak signal only just began to appear when DNA was extracted by spin column or conventional resin method (Fig. 2). When 200 cells were extracted a KUMC chelex method signal remained the same, while using the other two methods "T" peak signal now began to appear, though it was still lower than a KUMC chelex method. When 500 cells were extracted, there was no significant difference between the three methods.

Our KUMC chelex method provided superior efficiency for sequencing analysis of small numbers of cells.

\section{Discussion}

Most laboratories use benign and malignant epithelial cells for comparative evaluation as these are representative of samples that are frequently obtained for molecular diagnosis (Aplenc et al, 2002; Kim et al, 2008).

In this study, we compared three different DNA extraction methods using microdissected cells smeared on glass slides. DNA extraction from these microdissected cells is quite challenging because we have to deal with very small numbers of cells in most clinical settings.

Quantities of nucleic acids in solution are often estimated based on the absorbance of light at a wavelength of $260 \mathrm{~nm}$. An $\mathrm{A}_{260}$ of 1.0 correlates roughly with a double stranded DNA content of $50 \mu \mathrm{g} / \mathrm{mL}$. The $A_{280}$ is traditionally taken as a measure of protein content in a solution (though nucleic acids absorb a considerable amount of light at $280 \mathrm{~nm}$ ) and the $\mathrm{A}_{260} / \mathrm{A}_{280}$ ratio is a measure of the purity of the nucleic acid extract. $\mathrm{A}_{260} / \mathrm{A}_{280}$ ratios of $1.8 \pm 0.2$ are generally considered relatively free of protein contamination (Zhang et al, 2009). Celer et al were reported the QIAamp produced $\mathrm{A}_{260}$ value
$<0.10$, even with the 50,000 cell extraction. this is not unexpected when DNA extracted from paucicellular samples using methods that effectively exclude protein carryover. Purity of a KUMC chelex method appeared within the 1.5 to 1.8 range and demonstrated little protein contamination. This degree of contamination is expected when DNA is extracted from paucicellular samples. However, we had no problems amplifying the $\beta$-globin and $B R A F^{V 600 E}$ genes. A KUMC chelex method yielded the highest average DNA concentration and the best amplified $\beta$-globin gene products in all cell groups, especially in the lowest cell(50) group (Table 1, Fig. 1). The pyrosequencing assay was designed to begin sequence analysis right at the mutation site. A sequential nucleotide dispensation protocol was used that reflects the expected order of nucleotide incorporation and the potential base changes. Peak signal heights are proportional to the number of nucleotides that are incorporated with each dispensation (Zhang et al, 2009). When we used BRAF ${ }^{V 600 E}$ mutational analysis to determine the efficiency of DNA extraction, Fig. 2. showed significant difference in the sequence change when tumor cells that had been extracted from smeared samples were used. Most notably, when only 50 cells were extracted by a KUMC chelex method, both " $\mathrm{T}$ " peak signal height increase and adjacent "A" peak signal height decrease were present. This is in contrast to the two other methods, where sequence peaks were too low to be observed after DNA extraction (Fig. 2). These results suggest that our KUMC chelex method provided good quality and yield for molecular analysis of paucicellular clinical samples. The primary readout of this study was amplifiable DNA as measured by $B R A F^{V G O 0 E}$ mutation detection.

Previous studies concluded that while adequate quality and quantity of DNA could be obtained from small quantities of fine needle aspirate samples, yields might differ between DNA extraction methods (Cler et al, 2006; Hwang et al, 2009). Our KUMC chelex method gave higher DNA and PCR yields than both the pinpoint slide DNA isolation system ${ }^{\mathrm{TM}}$ (Zymo research, USA), which uses spin columns, and conventional ion exchange resin-based protocols (Takara Bio. Inc., Japan).

The increased yields in a KUMC chelex method may be attributed to the digestion with proteinase $\mathrm{K}$, components of 
the extraction buffer, or a synergistic effect of $\mathrm{pH}$ with heat which could increase cell lysis and thus DNA available for recovery. Proteinase $\mathrm{K}$ in the extraction buffer inactivates nucleases and aids in hydrolysis of epithelial, freeing nuclear DNA. Inactivating these nucleases preserves the DNA so that it can be extracted and purified. Proteinase $\mathrm{K}$ is active over a wide $\mathrm{pH}$ range (4-12.5) (Baechtel et al, 1989; Banerjee et al, 1995; Shi et al, 2002). KUMC chelex extraction buffer of alkaline conditions ( $\mathrm{pH} \mathrm{8-11)} \mathrm{and} \mathrm{add} \mathrm{of} \mathrm{proteinase} \mathrm{K}$ provided good quantity and quality of DNA. The most common mechanism of protein precipitation is insolubility at high concentration of salt, usually $\left(\mathrm{NH}_{4}\right)_{2} \mathrm{SO}_{4}$. It is based on the hydrophobic interaction of protein (Proteins and Enzymes, 2004). Our KUMC chelex extraction buffer included $\left(\mathrm{NH}_{4}\right)_{2} \mathrm{SO}_{4}$ which aids in the precipitation of protein with resin. The pinpoint slide DNA isolation system ${ }^{\mathrm{TM}}$ kit of adsorption of DNA onto a silica membrane may increase chance of DNA loss due to precipitation and serial washing steps. The DEXPAT ${ }^{\mathrm{TM}}$ kit of an ion exchange resin is decrease of DNA yield and purity because there is no cell digestion step due to extraction. We found that combining these ingredients in the KUMC chelex extraction buffer, optimizing $\mathrm{pH}$, and adding proteinase $\mathrm{K}$ provided the most suitable conditions for DNA extraction.

Since we are examining gene mutations using clinical samples; many of which have limited numbers of cells in a typical sample; reproducible and cost-effective DNA extraction methods are needed. There are many other DNA extraction methods and modifications that we did not evaluate. One caveat is that our conclusions may not be generalized to other applications, particularly those that use formalin-fixed tissues.

When compared efficiency for the commercially available DNA extraction kit, Compared to the pinpoint slide DNA isolation system ${ }^{\mathrm{TM}}$ kit (relative cost=1.0), the relative supply costs for the other methods were 0.3 for KUMC chelex method, 0.7 for conventional resin method. On the average, the KUMC chelex method and the DEXPAT ${ }^{\mathrm{TM}}$ kit required $1 \mathrm{~h}$ of technician time from start to finish, the pinpoint slide DNA isolation system ${ }^{\mathrm{TM}}$ kit $2 \mathrm{~h}$. KUMC chelex method performed digestion and spin steps from start to finish, the DEXPAT ${ }^{\mathrm{TM}}$ kit heating and spin steps, the pinpoint slide DNA isolation system $^{\mathrm{TM}}$ kit digestion and precipitation, serial washing steps. The KUMC chelex method provided the additional advantage of lower cost and simple step for the commercially available DNA extraction kit.

In conclusion, each of the methods we tested yielded amplifiable DNA, but a KUMC chelex method provided the most successful results when starting with a limited number of cells. A KUMC chelex method was the fastest, least expensive, and most efficient especially when used for paucicellular clinical samples.

\section{Acknowledgements: None \\ Funding: None \\ Conflict of interest: None}

\section{References}

1. Aplenc R, Orudjev E, Swoyer J, Manke B, Rebbeck T. Differential bone marrow aspirate DNA yields from commercial extraction kits. Leukemia 2002, 16:1865-1866.

2. Baechtel, F. S. The extraction, purification and quantification of DNA. In Proceedings of the International Symposium on the Forensic Aspects of DNA Analysis, 1989, 25-28. Washington, D.C.:U.S. Government Printing Office.

3. Banerjee SK, Makdisi WF, Weston AP, Mitchell SM, Campbell DR. Microwave-based DNA extraction from paraffin embedded tissue for PCR amplification. BioTechniques. 1995, 18:768-773.

4. Bofin AM, Ytterhus B, Martin C, O'Leary JJ, Hagmar BM. Detection and quantification of HER-2gene amplification and protein expression in breast carcinoma. Am J Clin Pathol. 2004, 122:110-119.

5. Bu D, Lewis C, Cler L, Elias K. Comparative real-time PCR for the detection of $c-M y c$, cyclin D1 and Her-2/neugene amplification in breast fine needle aspirates. Am Assoc Cancer Res. 2003.

6. Cler L, Bu D, Lewis C, Euhus D. A comparison of five methods for extracting DNA from paucicellular clinical samples. Molecular and Cellular Probes. 2006, 20:191-196.

7. Daneshwar P, Shahnoo SU, Khoyratty S. Genomic DNA Extraction From Victoria amazonica. Plant Molecular Biology Reporter. 2004, 22:195a-195j.

8. Euhus DM, Cler L, Shivapurkar N, Milchgrub S, Peters GN, Leitch AM, Heda S, Gazdar AF. Loss of heterozygosity in benign breast epithelium in relation to breast cancer risk. J Natl Cancer Inst. 2002, 94:858-860.

9. Glasel J.A. Validity of nucleic acid purities monitored by 260 nm/280 nm absorbance ratios. Biotechniques. 1995, 18:62-63. 
10. Hwang TS. Molecular Biologic Techniques in Cytopathologic Diagnosis. Korean J Pathol. Review, 2009, 43:387-392.

11. Isaacs C, Cavalli LR, Cohen Y, Pennanen M, Shankar LK, Freedman M, Haddad BR. Detection of LOH and mitochondrial DNA alterations in ductal lavage and nipple aspirate fluids from high-risk patients. Breast Cancer Res Treat. 2004, 84:99-105.

12. Kersting M, Friedl C, Kraus A, Behn M, Pankow W, Schuermann M. Differential frequencies of p16(INK4a) promoter hypermethylation, $p 53$ mutation, and $K$-ras mutation in exfoliative material mark the development of lung cancer in symptomatic chronic smokers. J Clin Oncol. 2000, 18:3221-3229.

13. Kim SK, Kim DL, Han HS, Kim WS, Kim SJ, Moon WJ, Oh SY, Hwang TS. Pyrosequencing Analysis for Detection of a BRAF ${ }^{V 600 E}$ Mutation in an FNAB Specimen of Thyroid Nodules. Diagn Mol pathol. 2008, 17:118-125.

14. Lewis CM, Cler LR, Bu DW, Zöchbauer-Müller S, Milchgrub S, Naftalis EZ, Leitch AM, Minna JD, Euhus DM. Promoter hypermethylation in benign breast epithelium in relation to predicted breast cancer risk. Clin Cancer Res. 2005, 11:166-172.

15. Phillips HA, Howard GC, Miller WR. Pilot studies on the $p 53$ gene in nipple aspirate fluid from patients with breast cancer. Breast Cancer Res Treat. 2000, 61:139-143.

16. Phillips HA, Howard GC, Miller WR. p53 mutations as a marker of malignancy in bladder washing samples from patients with bladder cancer. BrJ Cancer. 2000, 82:136-141.

17. Popa OP, Murariu D, Popa LO. Comparision of four DNA extraction method from invasive freshwater bivalve species (mollusca:bivalvia) in Romanian fauna. Travaux du Muséum National d'Histoire Naturelle "Grigore Antipa». 2007, L;527-536.

18. Salto-Tellez M, Koay ES. Molecular diagnostic cytopathology: definitions, scope and clinical Utility. Cytopathology. Review, 2004, 15:252-255.
19. Seripa D, Parrella P, Gallucci M, Gravina C, Papa S, Fortunato P, Alcini A, Flammia G, Lazzari M, Fazio VM. Sensitive detection of transitional cell carcinoma of the bladder by microsatellite analysis of cells exfoliated in urine. Int J Cancer. 2001, 95: 364-569.

20. Shi SR, Cote RJ, Wu L Liu C, Datar R, Shi Y, Liu D, Lim H, Taylor CR. DNA Extraction from Archival Formalin-fixed Paraffin-embedded Tissue Sections Based on the Antigen Retrieval Principle: Heating Under the Influence of $\mathrm{pH}$. J Histochem Cytochem. 2002, 50:1005-1011.

21. Vandenberg N, van Oorschot RAH, Mitchell RJ. An evaluation of selecte DNA extraction strategies for shot tanem repeat typing. Electophoresis. 1997, 18:1624-1626.

22. Walker AH, Najarian D, White DL, Jaffe JF, Kanetsky PA, Rebbeck TR. Collection of genomic DNA by buccal swabs for polymerase chain reaction-based biomarker assays. Environ Health Perspect. 1999, 107:517-520.

23. Wang SS, Thornton K, Kuhn AM, Nadeau JG, Hellyer TJ. Homogeneous real-time detection of single-nucleotide polymorphisms by strand displacement amplification on the BD ProbeTec ET system. Clin Chem. 2003, 49:1599-1607.

24. Zhang LF, Gao WM, Gealy R, Weissfeld J, Elder E, Whiteside TL, Keohavong P. Comparison of K-ras gene mutations in tumour and sputum DNA of patients with lung cancer. Biomarkers. 2003, 8:156-161.

25. Zhang L, Kiirchhoff T, Yee CJ, Offit K. A rapid and reliable test for BRCA1 and BRCA2 founder mutation analysis in paraffin tissue using pyrosequencing. J Mol Diagn. 2009, 11:176-181.

26. Protein Purification: Precipitation. 115:412/508, http:www. cook.rutgers.edu/ dbm/precipitations04. Proteins and Enzymes spring 2004. 